\title{
Ervin Beck, Mennofolk. Mennonite \& Amish Folk Traditions
}

Scottdale (Penn.), Herald Press, 2004, 230 p.

Régis Dericquebourg

\section{(2) OpenEdition}

\section{Journals}

Édition électronique

URL : http://journals.openedition.org/assr/5292

DOI : 10.4000/assr.5292

ISSN : 1777-5825

\section{Éditeur}

Éditions de l'EHESS

Édition imprimée

Date de publication : 1 juin 2007

Pagination : $97-251$

ISBN : 978-2-7132-2143-9

ISSN : 0335-5985

\section{Référence électronique}

Régis Dericquebourg, "Ervin Beck, Mennofolk. Mennonite \& Amish Folk Traditions », Archives de sciences sociales des religions [En ligne], 138 | avril - juin 2007, document 138-4, mis en ligne le 11 septembre 2007, consulté le 21 septembre 2020. URL : http://journals.openedition.org/assr/5292 ; DOI : https:// doi.org/10.4000/assr.5292

Ce document a été généré automatiquement le 21 septembre 2020

(C) Archives de sciences sociales des religions 


\section{Ervin Beck, Mennofolk. Mennonite \& Amish Folk Traditions}

Scottdale (Penn.), Herald Press, 2004, 230 p.

Régis Dericquebourg

1 L'auteur invite le lecteur à un voyage raisonné dans les productions artistiques et festives du mennonisme. Il prétend se situer dans les études des «folk cultures» de type sociologique et non dans celles de type «folkloriste » et refuse de placer son livre dans la veine des travaux sur la culture populaire. Pour lui, les productions qu'il commente sont des éléments d'une culture transmise consciemment en utilisant les canaux de communication disponibles à l'intérieur d'une communauté. Un exemple parmi d'autres serait la transmission de la musique, et en particulier des hymnes à l'intérieur du mennonisme. E. Beck veut montrer que les mennonites constituent un folk-groupe spécifique dont les branches locales possèdent au moins un trait commun : nous aurions affaire à un ensemble qui a développé en son sein des traditions qu'il considère comme siennes. Dans les faits, il existe des communautés anabaptistes dans le monde entier. Chaque groupe local est une incarnation de l'anabaptisme et cultive son folklore local ressemblant ainsi, selon l'auteur, aux groupes ethniques dans leurs différents contextes sociologiques.

2 Ervin Beck trouve comme éléments de la folk culture mennonite : 1. Les histoires drôles qui, selon lui, contribuent à valider la culture des mennonites, à justifier leur manière de vivre et à expliquer pourquoi ils vivent ainsi. En racontant des histoires les mettant en scène, les mennonites feraient dériver la critique qui les frappe vers d'autres groupes sociaux. L'humour constituerait, ainsi, une compensation puisqu'en se décrivant défavorablement, ils maîtriseraient la moquerie (comme forme de discrimination à leur égard) à la manière des histoires belges inventées par les Belges eux-mêmes ; 2. Les légendes urbaines qui circulent sur eux; 3. Les "protests songs" (anticonscription, anticapitalistes, pacifistes) composés par des mennonites dans les camps où ils faisaient leur service civil en tant qu'objecteurs de conscience pendant la Seconde Guerre mondiale. Ces chants, pour la plupart composés par Vincent Beck exclu de sa communauté mennonite, sont considérés comme des chants mennonites; 4 . La 
peinture sur verre (mottos) à laquelle sont associés des noms d'artiste comme Marie Yoder Miller (1931-) Katie Miller (1956-) Sarah Ellen Royer (1940-), Navette Miller (1968-). Elle ne représente pas d'êtres humains mais des motifs tels que des fleurs, des papillons, des paysages, des versets des Écritures. Les artistes peignent sur verre les commémorations d'anniversaires ou des éléments de généalogie familiale. La généalogie est, chez les mennonites, la forme la "plus vigoureuse " d'histoire et, de fait, un élément de leur histoire ; et enfin 5. Le "Relief Sale Festival » sur lequel l'auteur s'attarde en raison de son importance économique et des interprétations sociologiques qu'il suscite. L'auteur s'intéresse à la Michiana Mennonite Relief Festival qui se tient chaque année le quatrième samedi de septembre dans l'Indiana. Répertorié dans l'annuaire des festivités de cet État, ce festival est préparé par «les gens pour les gens ", il n'est donc pas une entreprise commerciale bien qu'il soit lucratif. Les mennonites n'y sont pas passifs; ils ne le considèrent pas comme un festival, ne se comportent pas comme des clients et y seraient donc authentiques. Pour l'auteur, le festival est l'expression d'une communauté qui suspend les règles de la vie quotidienne et qui réaffirme la cohésion d'un groupe social à sa structure communautaire à travers la participation à un moment de revitalisation cosmique aussi bien que social et culturel. Le festival se situe dans l'extra-quotidienneté. Les faits qui s'y produisent sont considérés, par l'auteur, comme des rites: rite de valorisation d'un moment de la communauté, rite de consommation, rites de compétition (avec les jeux proposés), rites d'échange (entre les classes moyennes qui consomment et les pauvres de l'Indiana qui en recevront le produit), rites de l'inversion de la vie quotidienne car, à la frugalité quotidienne, les mennonites substituent la dépense d'argent ; ils inversent les rôles car ce sont les femmes qui se chargent du festival ; renversement de la hiérarchie clercslaïques. Inversion du pouvoir : la démocratie qui règne dans la préparation et dans le fonctionnement $\mathrm{du}$ festival trancherait avec la gestion hiérarchique de la vie quotidienne mennonite. L'inversion serait thérapeutique à la manière des carnavals pendant lesquels beaucoup d'interdictions sont suspendues, ce qui donne le sentiment de se libérer de l'emprise des contraintes quotidiennes.

On peut comparer ces festivals organisés par un groupe pour ses membres à une fête de l'école privée préparée par les parents d'élèves pour eux-mêmes et leurs proches: l'école s'y valorise, fait un bénéfice, les mères d'élèves préparent des broderies qui y seront vendues; les parents ont un rôle prépondérant sur celui des enseignants. On peut penser aux nombreux carnavals du Nord de la France pendant lesquels on sort les géants : préparés par la population avec toutes les associations locales : ils sortent de l'extra-quotidienneté et bousculent des pratiques sociales établies. Mais faut-il considérer comme des rites les éléments sociologiques qu'Ervin Beck met en évidence et interprète ? Pourquoi faire d'une auto-valorisation du groupe un rite de valorisation quand il n'y a pas de codage traditionnel de cette valorisation? Ou un rite d'inversion quand il n'y a pas de trame scénique fixée pour montrer que la frugalité cède la place à une consommation dispendieuse. Et quand la part active des femmes dans la préparation et le déroulement de la fête ne semble pas ritualisée?

4 Toutefois, ce livre est précieux pour connaître d'autres facettes du mennonisme. 